\title{
Análise de Dois Sistemas de Produção Pecuária Aplicando um Modelo de Gestão
}

\section{Analysis of two Livestock Production Systems Applying a Management Model}

\author{
Rafael Capriolli Gonçalves; José Antonio Maior Bono*a; José Francisco dos Reis Neto ${ }^{\mathrm{a}}$ \\ a'Universidade Anhanguera-Uniderp, Programa de Pós-Graduação Stricto Sensu em Produção e Gestão Agroindustrial. MS, Brasil. \\ *E-mail: bono@anhanguera.com
}

\begin{abstract}
Resumo
O setor da agropecuária no Brasil, apresentou, nos últimos quinze anos, crescimento econômico, e como resultado, o país se tornou um dos grandes produtor e exportador de produtos de origem animal. O segmento, que ainda tem potencial de expansão, depende de inovação e tecnologias a serem adotadas, como modelos de gestão na propriedade rural, permitindo avaliar seu desempenho e sua tomada de decisão. O objetivo deste trabalho é aplicar um sistema de gestão em duas propriedades com sistemas diferenciados de produção na pecuária, mensurando o desempenho econômico e zootécnico, proporcionado ao produtor informações para sua tomada de decisão no seu sistema de produção. Para este estudo foram selecionadas duas propriedades, uma localizada no município de Lambari do Oeste-MT, que adota o sistema de produção de cria, recria e engorda e outra no município de Bandeirantes-MS, que utiliza o sistema de recria e engorda. O período de estudo compreendeu os anos de 2015 a 2017, utilizando os dados registrados pelos próprios produtores. A partir dos dados gerados pelo sistema de gestão, foi possível a análise mais detalhada dos custos de produção e a influência da rentabilidade nas atividades das fazendas. Os resultados indicaram que o desempenho econômico é diretamente influenciado pelo gerenciamento dos custos de produção. As informações geradas pelo sistema de gestão para o produtor, proporcionou a tomada de decisões mais adequadas para a propriedade rural.
\end{abstract}

Palavras-chave: Agropecuária. Recursos de Produção. Sistema de Gestão. Tomada de Decisão. Controle Financeiro.

\begin{abstract}
The agricultural sector in Brazil has shown economic growth in the last fifteen years, and as a result the country has become one of the major producers and exporters of animal products. The segment, which still has expansion potential, depends on innovation and technologies to be adopted, such as the adoption of management models in rural property, allowing to evaluate its performance and decision making. The objective of this work is to apply a management system in two properties with differentiated production systems in livestock, measuring the economic and zootechnical performance, provided to the producer information for his decision making in his production system. For this study, we selected three properties, one located in the county of Lambari do Oeste-MT, which adopts the production system of rearing, rearing and fattening and another in the county of Bandeirantes-MS, which uses the system of rearing and fattening. The study period comprised the years 2015 to 2017, using the data recorded by the producers themselves. From the data generated by the management system, it was possible to more detailed analysis of production costs and the influence of profitability on farm activities. The results indicated that economic performance is directly influenced by the management of production costs. The information generated by the management system for the producer, provided the most appropriate decision-making for farm property.
\end{abstract}

Keywords: Livestock Production. Production Resources. Management System. Decision Making. Financial Control.

\section{Introdução}

O Brasil, no setor agropecuário, apresentou nos últimos quinze anos um crescimento levando este segmento a destaque mundial, na produção de carne bovina. No entanto, este avanço ficou abaixo do real potencial para a atividade, necessitando da melhoria da gestão dos recursos de produção (SILVA et al., 2010).

A atividade agropecuária tem que levar em consideração a sua administração, tornando suas tomadas de decisões e planejamento mais dinâmico, essencial para sua melhor eficiência (SALUME et al., 2015; NAGAOKA et al., 2011).

A ferramenta que propõem um controle financeiro é comentada por Matsunaga et al. (1976), em que a estrutura é separada por itens que compõem o Custo Operacional Efetivo (COE), o Custo Operacional Total (COT) e o Custo
Total (CT). Este sistema é adotado pelo Centro de Estudos Avançados em Economia Aplicada - CEPEA/ESALQ, que elabora e disponibiliza boletins trimestrais (CEPEA, 2016, 2017).

Os fatores que envolvem o sistema de produção da agropecuária como: planejar, organizar, dirigir e controlar, devem estar interligados para uma gestão com êxito nos resultados (BREITENBACH, 2014). Silva Pereira et al. (2013) consideram que a gestão destes fatores seria um dos principais entraves para o crescimento do setor agropecuário brasileiro.

O objetivo deste trabalho foi aplicar um método de gestão em dois sistemas de produção na pecuária, visando mensurar o desempenho econômico e zootécnico, para possibilitar melhorar o planejamento das atividades. 


\section{Desenvolvimento}

\subsection{Metodologia}

O trabalho foi desenvolvido em duas propriedades, uma localizada no município de Lambari do Oeste-MT, que só adota o sistema de produção de cria, recria e engorda a pasto e a outra no município de Bandeirantes-MS, que só utiliza o sistema de produção intensivo de recria e engorda com confinamento e semiconfinamento.

\subsubsection{Propriedade com sistema de cria, recria e engorda}

A Fazenda Primavera está localizada no município de Lambari do Oeste-MT, na margem esquerda do Rio Onça Magra, coordenadas de latitude $15^{\circ} 24^{\prime} 08^{\prime \prime} S$ e longitude 57³4'58'W. A propriedade dispõe de uma área total de 989 ha, sendo 460 ha de pastagem de Brachiaria decumbens, destinada ao sistema de produção extensiva, sendo dividida em 12 pastos com módulos de 30 a 60 ha. A mão de obra é formada por dois funcionários.

O gado é da raça nelore e o número de animais está em função da capacidade de suporte, adequada conforme os meses de maior produção de forragem, que se refere ao período das águas, de novembro a abril. Nos meses de maior restrição, sendo caracterizada pela seca, que compreende o período de maio a outubro, em função dos pastos degradados e da escassez de chuva, ocorre uma redução na oferta de alimentos (pastagem).

A fazenda em questão mantém uma carga animal média de aproximadamente 882 cabeças (várias eras). Com relação ao cronograma de atividades, a fazenda possui a prática de estação de monta, que compreende os meses de novembro a fevereiro, com nascimento os bezerros no período de julho a outubro. Os bezerros são desmamados no período de março a junho, próximo a sete meses de idade.

Os animais são criados, exclusivamente, em sistema de pastagem. São vacinados contra febre aftosa, raiva, clostridiose e brucelose (fêmeas) e recebem vermífugo de amplo espectro. O controle de moscas e carrapatos é realizado conforme a infestação.

Os animais comercializados são bois de 4 anos de idade, vacas de descarte ( 3 a 4 anos de idade) e novilhas de 2 a 3 anos de idade. Os animais, machos e fêmeas, são direcionados para recria e permanecem na fazenda por quatro anos, o mesmo acontece com os animais para engorda.

A vermifugação nos bezerros é efetuada mensalmente, e nos demais animais é realizada uma vermifugação estratégica feita três vezes ao ano, nos meses de maio, julho e setembro. Conforme a necessidade, é realizado o controle de ectoparasitas.

A suplementação mineral é oferecida no cocho o ano inteiro. $\mathrm{Na}$ fase de engorda tem-se um período de 6 a 8 meses em pastagens de boa qualidade, oferecendo na fase terminal um sal proteico.

\subsubsection{Propriedade com sistema de cria e engorda}

A propriedade Cabeceira da Lagoa adota o sistema de sistema de produção de recria e engorda com confinamento e semiconfinamento, e está localizada no município de Bandeirantes - MS nas coordenadas de latitude $19^{\circ} 48^{\prime} 8.54^{\prime \prime} \mathrm{S}$ e longitude $54^{\circ} 11^{\prime} 5.85^{\prime} \mathrm{O}$.

Apresenta uma área total de 1.200 ha, sendo 950 ha de pastagens efetivas. As pastagens utilizadas são Brachiaria brizantha, cultivares Marandu e Piatã e Brachiaria humidicola e Brachiaria decumbens. As pastagens são divididas em piquetes de 15 a 30 ha, variando de acordo com as espécies forrageiras e tipo de solo, utilizando um sistema rotacionado de manejo das pastagens com as categorias de recria de animal e acabamento em sistema de semiconfinamento e confinamento.

A carga animal destas pastagens é de 1,9 UA ano, utilizando machos anelorados. Estes animais são adquiridos na região dos municípios de Bandeirantes, Jaraguari, Camapuã, Figueirão e Alcinópolis. Os animais entram na propriedade entre 210 a $260 \mathrm{~kg}$ de peso vivo, são brincados e realizados tratamentos sanitários (vacinas e vermífugos). Os animais permanecem no sistema de recria até atingirem entre 370 a $400 \mathrm{~kg}$ de peso vivo. Após, são colocados no semiconfinamento ou no confinamento, dependendo da época do ano. O confinamento ocorre no período de maio a setembro e o semiconfinamento de setembro a abril.

A propriedade dispõe de estrutura para confinar até 1500 cabeças, com preparo da ração no próprio local. Os insumos básicos como milho, torta de algodão ou soja, núcleo, volumoso (bagaço de cana ou casquinha de algodão, dependendo da disponibilidade e preço) são adquiridos na região de São Gabriel do Oeste e Chapadão do Sul, para compor a ração do confinamento e ou semi-confinamento.

\subsubsection{Levantamento dos dados}

Os dados referentes ao inventário ligado a atividade, depreciações, variação do tamanho do rebanho, custo fixo, custo variável, despesas administrativas, custo operacional e custo total dos anos de 2015, 2016 e 2017, foram fornecidos pelos respectivos proprietários, através de registros das informações que os produtores dispunham e os mesmos colocados no Sistema Gerencial de Análise de Custos na Pecuária de Corte, de Aguiar e Rezende (2010).

Os resultados obtidos pelo sistema de gestão foram estruturados conforme a proposta de custo de produção descrita por Matsunaga et al. (1976), composta pelo Custo Operacional Efetivo (COE), o Custo Operacional Total (COT) e o Custo Total (CT). Em seguida foram comparados com os relatórios trimestrais gerados pelo CEPEA (Centro de Estudos Avançados em Economia Aplicada), que elabora o custo de produção de pecuária de corte desde 2003 (CEPEA, 2016, 2017).

Os valores apresentados em 2015, 2016 e 2017 foram corrigidos para o valor presente de dezembro de 2017, 
calculado a partir dos dados básicos da correção do IPC-A (IBGE, 2017).

Os indicadores de desempenho zootécnicos aplicados nas propriedades, adotam à metodologia baseada na Embrapa Gado de Corte, sendo selecionados a Taxa de Lotação (UA ha${ }^{1}$ ); Produção de arroba ha-1 (ano); Desembolso por cabeça por ano, Lucro por hectare por ano e a Taxa de desfrute.

\subsection{Discussão}

\subsubsection{Sistema de cria, recria e engorda a pasto}

No Quadro 1, encontra-se o resumo que a ferramenta de gestão gerou, indicando a taxa de lotação média foi de 1,4 $\left(\mathrm{UA} \mathrm{ha}^{-1}\right)$, valor acima da média nacional de $0,8\left(\mathrm{UA} \mathrm{ha}^{-1}\right)$ conforme dados do relatório da ANUALPEC (2014).

Quadro 1 - Dados do rebanho bovino no período de 2015 a 2017 da Fazenda Primavera localizada no município de Lambari do Oeste - MT

\begin{tabular}{|c|c|c|c|c|}
\hline Dados do Rebanho & 2015 & 2016 & 2017 & Média \\
\hline Total (cabeças) & 892 & 897 & 858 & 882 \\
\hline Peso Médio/Cabeça & 353 & 350 & 349 & 349 \\
\hline Estoque em @ & 10.501 & 10.459 & 9.975 & 10.312 \\
\hline Área Útil (ha) & 460 & 460 & 460 & 460 \\
\hline $\begin{array}{l}\text { Densidade de Lotação } \\
\left(\text { cabeça ha }^{-1}\right)\end{array}$ & 1,9 & 1,9 & 1,9 & 1,9 \\
\hline $\begin{array}{l}\text { Taxa de Lotação (UA ha } \\
\text { ano }^{-1} \text { ) }\end{array}$ & 1,5 & 1,5 & 1,4 & 1,4 \\
\hline
\end{tabular}

Fonte: Dados da pesquisa.

O Quadro 2 apresenta os dados da receita bruta. O ano de 2015 apresentou a menor receita bruta, totalizando R\$ 287.341,00, devido ao menor número de animais comercializados. Nos anos de 2016 e 2017 nota-se que os totais das receitas brutas foram expressivos, aumentando em relação ao ano de 2015, em torno de $21 \%$ no ano de 2016 , e de $9 \%$ em 2017.

Quadro 2 - Receita bruta (R\$) obtida com sistema de produção de cria, recria e engorda da Fazenda Primavera localizada no município de Lambari do Oeste - MT

\begin{tabular}{|l|c|c|c|c|}
\hline Receita Bruta & 2015* & 2016* & 2017* & Média \\
\hline Boi Gordo (Abate) & 168.607 & 199.892 & 481.729 & 283.409 \\
\hline Vaca (Abate) & 118.733 & 123.755 & 33.485 & 91.991 \\
\hline Novilhas & 0 & 150.554 & 0 & 50.185 \\
\hline Receita Total & 287.341 & 474.201 & 515.214 & 425.585 \\
\hline
\end{tabular}
*valores corrigidos em R\$ a dezembro de 2017 pelo IPC-A do IBGE
Fonte: Dados da pesquisa.

No Quadro 3, verifica-se que o lucro operacional por ha (hectare) no ano 2015 foi negativo, perfazendo um total $\mathrm{R} \$-26 \mathrm{ha}^{-1}$. Isso denota que a taxa de desfrute do gado foi baixa no decorrente ano. Já nos anos de 2016 e 2017, ocorreu uma recuperação do lucro operacional por ha, perfazendo em 2016 um lucro de R\$ 347 ha $^{-1}$ e em 2017 de R\$ 556 ha $^{-1}$, demonstrando que quanto maior a taxa de desfrute do sistema de produção de cria, recria e engorda, maior será o lucro obtido por ha.
Quadro 3 - Indicadores financeiros da atividade do sistema de produção de cria, recria e engorda da Fazenda Primavera localizada no município de Lambari do Oeste - MT

\begin{tabular}{|l|c|c|c|}
\hline \multicolumn{1}{|c|}{ Indicador Financeiro } & $\mathbf{2 0 1 5}^{*}$ & $\mathbf{2 0 1 6}^{*}$ & $\mathbf{2 0 1 7} *$ \\
\hline Lucratividade \% ano $^{-1}$ & $-4,2 \%$ & $33,7 \%$ & $49,6 \%$ \\
\hline Lucro operacional ha $^{-1}$ (ano) & $(26)$ & 347 & 556 \\
\hline $\begin{array}{l}\text { Custo operacional por cabeça } \\
\text { ano }^{-1}\end{array}$ & 228 & 350 & 304 \\
\hline
\end{tabular}

Fonte: Dados da pesquisa.

Houve prejuízo para a atividade no ano de 2015, apresentando um índice de $-4,2 \%$, demonstrando que a baixa taxa de desfrute influenciou negativamente em todos os indicadores financeiros. Nota-se que no período em estudo, a lucratividade apresentou o seu melhor desempenho no ano de 2017, com um índice de 49,6\%.

O custo operacional por cabeça/ano ficou em torno de R\$ 228 em 2015, R\$ 350 em 2016 e R\$ 304 em 2017. Esse indicador demonstra ao proprietário o quanto o custo variável, custo fixo e as depesas admininstrativas podem interferir no custo operacional efetivo, podendo identificar a causa, realizando uma alteração e estabelecendo um ganho adicional em cada unidade animal.

A produção de arroba ha $^{-1}$ (ano) apresentada na Tabela 4 , demonstra que a média do período foi de 10,5 arroba ha ${ }^{-1}$ (ano), evidenciando que é um dos indicadores que merece atenção por sofrer influência da lotação $\left(\mathrm{UA} \mathrm{ha}^{-1}\right)$, do ganho de peso diário, das taxas reprodutivas e mortalidade. Conforme Embrapa Cerrados (2005), a média brasileira não chega a 3 arroba ha ${ }^{-1}$ (ano), sendo que o alvo das empresas agropecuárias deva superar 10 arroba ha-1 (ano).

Quadro 4 - Indicadores zootécnicos anuais da atividade do sistema de produção de cria, recria e engorda, no período de 2015, 2016 e 2017 da fazenda Primavera, localizada no município de Lambari do Oeste - MT

\begin{tabular}{|l|c|c|c|}
\hline Indicadores Zootécnicos & $\mathbf{2 0 1 5}$ & $\mathbf{2 0 1 6}$ & $\mathbf{2 0 1 7}$ \\
\hline $\begin{array}{l}\text { Produção de arroba ha- } \\
\text { (ano) }\end{array}$ & 10,67 & 10,72 & 10,25 \\
\hline Taxa de Desfrute & $11 \%$ & $13 \%$ & $21 \%$ \\
\hline Taxa de Natalidade & $66 \%$ & $67 \%$ & $64 \%$ \\
\hline
\end{tabular}

Fonte: Dados da pesquisa.

A taxa de desfrute foi se elevando no decorrer do período, apresentando sua maior taxa no ano de 2017, com $21 \%$. El-Memari Neto (2011) afirma que em sistemas de recria/ engorda o desfrute deve superar $50 \%$, já no ciclo completo (cria, recria e engorda) esse valor deve ultrapassar os $40 \%$. Isso demonstra que a propriedade está praticando uma taxa de desfrute de $19 \%$ a menor, em relação ao que o mercado considera aceitável, o que cabe uma tomada de decisão quanto ao sistema de produção, para elevar a produção de arroba ha-1 (ano).

Quanto a taxa de natalidade, a propriedade apresentou um índice médio de $65,83 \%$, ficando próximo do índice praticado no sistema de produção da pecuária extensiva no Brasil, que é de 70\% (ANUALPEC, 2014), indicando que se aproxima da 
expectativa praticada no segmento de mercado.

\subsubsection{Sistema de recria e engorda em confinamento e semiconfinamento}

No ano de 2015, a taxa de lotação era de 1,2(UA ha-1), ano o qual a propriedade alterou do sistema de cria, recria e engorda, para o sistema de produção intensivo de recria e engorda no sistema de confinamento e semiconfinamento. Nos anos subsequentes, os valores para a taxa de lotação aumentaram, chegando em 2016 a 1,7(UA ha-1) e em 2017 a 1,9(UA ha ${ }^{-1}$ ) (Quadro 5). De acordo com o anuário da pecuária brasileira - ANUALPEC (2014), a taxa de lotação média no ciclo de produção de recria e engorda, é de 1,51(UA ha-1). Dessa forma, a taxa de lotação da propriedade foi superior aos praticados na média brasileira.

Quadro 5 - Rebanho no período de 2015, 2016 e 2017, para o sistema de produção intensivo de recria e engorda da fazenda Cabeceira da Lagoa, localizada no município de BandeirantesMS

\begin{tabular}{|l|c|c|c|c|}
\hline Dados do Rebanho & $\mathbf{2 0 1 5}$ & $\mathbf{2 0 1 6}$ & $\mathbf{2 0 1 7}$ & Média \\
\hline Total (cabeças) & 1.929 & 1.725 & 1.914 & 1.856 \\
\hline Peso Médio/Cabeças & 255 & 417 & 423 & 365 \\
\hline Estoque em @ & 16.420 & 23.985 & 27.001 & 22.469 \\
\hline Área útil (ha) & 950 & 950 & 950 & 950 \\
\hline $\begin{array}{l}\text { Densidade de Lotação } \\
\text { (cabeça ha }^{-1} \text { ) }\end{array}$ & 2,0 & 1,8 & 2,0 & 1,9 \\
\hline $\begin{array}{l}\text { Taxa de Lotação (UA } \\
\text { ha ano } \text { and }^{-1}\end{array}$ & 1,2 & 1,7 & 1,9 & 1,6 \\
\hline
\end{tabular}

Fonte: Dados da pesquisa.

A receita bruta, apresentada no Quadro 6, demonstra que no ano de 2015, além da venda de animais em engorda, a propriedade também obteve rendimentos a partir do aluguel de trator e pastagens, totalizando um montante de R \$ 2.345.279.

Quadro 6 - Receita bruta obtida com sistema de produção intensivo de recria e engorda da fazenda Cabeceira da Lagoa, localizada no município de Bandeirantes-MS

\begin{tabular}{|l|c|c|c|c|}
\hline $\begin{array}{c}\text { Receita } \\
\text { Bruta }\end{array}$ & $\mathbf{2 0 1 5 *}$ & $\mathbf{2 0 1 6 *}$ & $\mathbf{2 0 1 7 *}$ & Média \\
\hline $\begin{array}{l}\text { Boi Gordo } \\
\text { (Abate) }\end{array}$ & 2.291 .631 & 4.722 .227 & 4.256 .441 & 3.756 .766 \\
\hline $\begin{array}{l}\text { Aluguel de } \\
\text { Trator }\end{array}$ & 36.330 & 0 & 0 & 12.110 \\
\hline $\begin{array}{l}\text { Aluguel de } \\
\text { pasto }\end{array}$ & 17.317 & 0 & 0 & 5.772 \\
\hline Total & 2.345 .279 & 4.722 .227 & 4.256 .441 & 3.774 .649 \\
\hline
\end{tabular}

*valores corrigidos em R\$ a dezembro de 2017 pelo IPC-A do IBGE.

Fonte: Dados da pesquisa.

Ao analisar a receita bruta nos anos de 2016 e 2017, verifica-se um incremento substancial, perfazendo um montante de R \$ 4.722.227,00 em 2016 e de R\$ 4.256.441,00 em 2017, que em comparação com a receita bruta de 2015 , aumentou 181\%. Quanto a participação das receitas geradas a partir das atividades praticadas, verifica-se que 99,53\% é proveniente da venda de boi gordo para abate.

No Quadro 7, verifica-se que o ano de 2016 apresentou o melhor lucro operacional por ha, perfazendo um total $\mathrm{R} \$$
$1.925,00 /$ ha. Isso denota que a taxa de desfrute do gado foi elevada, já que o sistema de produção intensivo estava em sua plenitude. Analisando o ano de 2017, foram adquiridos animais para engorda que não foram abatidos dentro do período contábil de 2017, impactando diretamente no lucro operacional por ha, perfazendo um lucro de R\$1.094,00.

Quadro 7. Indicadores financeiros da atividade do sistema de produção intensivo de recria e engorda da fazenda Cabeceira da Lagoa, localizada no município de Bandeirantes-MS

\begin{tabular}{|l|c|c|c|}
\hline \multicolumn{1}{|c|}{ Indicadores Financeiros } & $\mathbf{2 0 1 5}$ & $\mathbf{2 0 1 6}$ & \multicolumn{1}{|c|}{$\mathbf{2 0 1 7}$} \\
\hline${\text { Lucratividade } \% \text { ano }^{-1}}$ & $49,3 \%$ & $38,7 \%$ & $24,4 \%$ \\
\hline Lucro operacional ha ano $^{-1}$ & 1.217 & 1.925 & 1.094 \\
\hline $\begin{array}{l}\text { Custo operacional por cabeça } \\
\text { ano }^{-1}\end{array}$ & 640 & 1.668 & 1.669 \\
\hline
\end{tabular}

*valores corrigidos em R\$ a dezembro de 2017 pelo IPC-A do IBGE. Fonte: Dados da pesquisa

O custo operacional com reposição por cabeça ano ${ }^{-1}$ ficou em torno de R\$ 640 em 2015, R\$ 1.668 em 2016 e R\$ 1.669 em 2017. Conforme o relatório Agromensal bovino elaborado pela CEPEA-ESALQ (2017), o preço médio da arroba do boi em 2017 foi de R\$ 138,80, onde considerando um boi para abate com 22@, o mesmo gerou um valor de venda de R\$ $3.053,6$, verificando que o custo operacional com a reposição por cabeça de 2017 , representou 55\% do valor da venda de um animal. É possível verificar, também, que o custo operacional por arroba com reposição em 2017, ficou $14,55 \%$ a maior que a média do preço da arroba por ano, sendo influenciado pelos custos com a aquisição de animais e a suplementação alimentar. Com base nos dados apresentados pelo sistema de gestão, o proprietário deve adotar medidas para reduzir os custos de produção, com foco na aquisição de animais e suplementação alimentar.

A produção de arroba ha ${ }^{-1}$ ano $^{-1}$ confirma que o sistema de produção de cria e engorda elevou a produtividade da fazenda no período em estudo, saindo de 8,04 arroba ha-1 ano em 2015, para 11,08 arroba ha-1 ano no ano de 2017 (Quadro 8). Esse indicador merece atenção, já que retrata o montante de arroba por ha obtidos no ano, determinando ao produtor rural a tomada de decisão na maximização dos lucros a serem alcançados. Segundo a Embrapa Cerrados (2005), a média brasileira não chega a 3 arroba ha-1 (ano), sendo que uma boa meta para as empresas agropecuárias é superar 10 arroba ha-1 (ano).

Quadro 8 - Indicadores zootécnicos da atividade do sistema de produção intensivo de recria e engorda da fazenda Cabeceira da Lagoa, localizada no município de Bandeirantes-MS

\begin{tabular}{|l|c|c|c|}
\hline Indicadores Zootécnicos $^{-1}$ & $\mathbf{2 0 1 5}$ & $\mathbf{2 0 1 6}$ & $\mathbf{2 0 1 7}$ \\
\hline Produção de arroba ha $^{-1}$ (ano) & 8,04 & 9,99 & 11,08 \\
\hline Taxa de Desfrute (ano) & $1,4 \%$ & $8,9 \%$ & $20,7 \%$ \\
\hline
\end{tabular}

Fonte: Dados da pesquisa

A taxa de desfrute foi crescente no decorrer do período, apresentando sua maior taxa no ano de 2017, com 20,7\%. De 
acordo com Gomes et al. (2017), o aumento nos índices de desfrute do rebanho tem evoluído de aproximadamente $15 \%$ para até $25 \%$. Esses ganhos foram possíveis graças a crescente adoção de tecnologias pelos produtores rurais, especialmente nos eixos de alimentação, genética, manejo e saúde animal. Isso demonstra que a propriedade está praticando uma taxa de desfrute aceitável, o que cabe uma tomada de decisão quanto ao sistema de produção para elevar a produção de arroba ha-1 (ano).

\section{Conclusão}

A ferramenta de gestão aplicada aos sistemas de produção permitiu a análise mais detalhada dos custos de produção e a influência da rentabilidade. Proporcionou também, verificar os pontos de racionalização de custos, favorecendo um planejamento para redução do custo de produção.

Evidenciou-se, através da gestão dos fatores de produção, a importância de uma boa gestão, para a tomada de decisões adequadas para a propriedade rural de acordo com as oportunidades que o mercado e a região oferecem para alavancar os lucros dentro de cada realidade das propriedades em estudo.

\section{Referências}

AGUIAR, A.P.; RESENDE, J.R. Pecuária de corte: custos de produção e análise econômica. Viçosa: Aprenda Fácil, 2010.

ANUALPEC. Anuário da Pecuária Brasileira. São Paulo: Instituto/FNP, 2014.

ARTUZO, F.D. et al. Utilização da tecnologia de informação em propriedades rurais: um caso no município de Getúlio Vargas (RS). Rev. Agro. Meio Amb., v.9, n.2, p.305-322, 2016.

BREITENBACH, R. Gestão rural no contexto do agronegócio: desafios e limitações. Rev. Desafio Online.,v.1, n.2, p.714-731, 2014.

CEPEA. Centro de Estudos Avançados em Economia Aplicada. Análise Conjuntural Agromensal Pecuária: dezembro 2017. Piracicaba: CEPEA/ESALQ/USP/CNA, 2017.

CEPEA. Centro de Estudos Avançados em Economia Aplicada. Custos trimestrais bovinos: $4^{\circ}$ trimestre 2016. Piracicaba: CEPEA/ESALQ/USP/CNA, 2016.

CEPEA. Centro de Estudos Avançados em Economia Aplicada. Custos trimestrais bovinos: $4^{\circ}$ trimestre 2017. Piracicaba: CEPEA/ESALQ/USP/CNA, 2016.

EL-MEMARI NETO, A. C. Gestão de Sistemas de Produção de Bovinos de Corte. In: SIMPÓSIO MATO-GROSSENSE DE BOVINOCULTURA DE CORTE, 1, 2011, Cuiabá. Anais... Cuiabá: UFMT, 2011.

EMBRAPA CERRADOS. III Plano Diretor: Embrapa Cerrados: 2004-2007. Planaltina: Embrapa Cerrados, 2005.

GOMES, R.C.; FEIJÓ, G.L.D.; CHIARI, L. Evolução e qualidade da pecuária brasileira. Campo Grande: Embrapa Gado de Corte, 2017.

IBGE. Instituto Brasileiro de Geografia e Estatística. Produção da pecuária municipal 2016. Rio de Janeiro: IBGE, 2017.

MATSUNAGA, M. et al. Metodologia de custo de produção utilizada pelo IEA. Agric. São Paulo, v.23, n.1, p.123-139, 1976.

NAGAOKA, M.P.T. et al. Gestão de propriedades rurais: processo estruturado de revisão de literatura e análise sistêmica. Rev Bras. Agrociê., v.17, n.4, p.410-419, 2011.

SALUME, J. A.; SILVA, E.C.G.; CHRISTO, B.F. Elementos de administração rural avaliados em pequenas propriedades rurais de Alegre - ES. Cad. Prof. Adm. UNIMEP, v.5, n.1, p.76-93, 2015.

SILVA, M.Z.; RECH, L.C.; RECH, G.M. Estudo sobre as práticas de gestão utilizadas no gerenciamento das pequenas propriedades rurais de Guaramirim. Rev. Ciênc. Soc. Perspectiva, v.9, n.17, p.57-74, 2010. 